\title{
Review
}

\section{IAPs on the move: role of inhibitors of apoptosis proteins in cell migration}

\author{
TK Oberoi-Khanuja ${ }^{1}$, A Murali ${ }^{1}$ and K Rajalingam ${ }^{*, 1}$
}

Inhibitors of Apoptosis Proteins (IAPs) are a class of highly conserved proteins predominantly known for the regulation of caspases and immune signaling. However, recent evidence suggests a crucial role for these molecules in the regulation of tumor cell shape and migration by controlling MAPK, NF- $\kappa$ B and Rho GTPases. IAPs directly control Rho GTPases, thus regulating cell shape and migration. For instance, XIAP and cIAP1 function as the direct E3 ubiquitin ligases of Rac1 and target it for proteasomal degradation. IAPs are differentially expressed in tumor cells and have been targeted by several cancer therapeutic drugs that are currently in clinical trials. Here, we summarize the current knowledge on the role of IAPs in the regulation of cell migration and discuss the possible implications of these observations in regulating tumor cell metastases.

Cell Death and Disease (2013) 4, e784; doi:10.1038/cddis.2013.311; published online 5 September 2013

Subject Category: Cancer

Facts

- IAPs directly regulate cell shape, migration and tumor metastases.

- IAPs have pro- and anti-migratory roles depending on the cellular context.

- IAPs can regulate the plasticity of tumor cell migration by affecting the stability and activation of Rho GTPases.

- IAPs have been correlated with both negative and positive tumor prognosis.

\section{Open Questions}

- What is the role of IAPs in regulating physiological forms of cell migration like wound healing?

- What are the distinct roles of different IAPs in tumor metastasis?

- What are the various signaling pathways activated by IAP antagonists in the context of tumor cell invasion?

\section{Inhibitor of Apoptosis Proteins (IAPs)}

Inhibitor of apoptosis proteins (IAPs), also known as BIRCs (BIR domain containing proteins) are a class of proteins characterized by the presence of Baculovirus IAP Repeat (BIR) domain, a $\mathrm{Zn}^{2+}$ ion coordinating protein-protein interaction motif. They are highly conserved from viruses to mammals and were discovered in a genetic screen of baculoviral genome as inhibitors of host programmed cell death machinery, hence named IAPs. ${ }^{1,2}$ However, recent advances in the field of IAP/BIRC biology strongly establish these proteins to be pivotal for numerous cellular signaling networks. Studies from other organisms down the evolutionary ladder have also revealed that IAPs are pleotropic proteins and not just inhibitors of caspases. Certain prokaryotes, yeasts and plants undergo a form of programmed cell death (PCD) by caspase homologs known as metacaspases. ${ }^{3}$ Yet no IAP homologs are found in prokaryotes and plants; and metacaspases are also not essential for prokaryotic PCD. In case of $S$. cerevisiae, the only known IAP, BIR1p inhibits apoptosis in a YCA1 (S. cerevisiae metacaspase)-independent manner. BIR1p is required for proper chromosome segregation and cytokinesis and moreover, YCA1 also has roles in cell cycle regulation, clearance of protein aggregates, and so on. ${ }^{4-6}$ Further, though there are viral IAP homologs, caspase homologs have not been identified in viruses. ${ }^{1,2}$

There are eight known mammalian IAPs/BIRCs (Figure 1): BIRC1 (neuronal IAP/NAIP), BIRC2 (cellular IAP1/CIAP1/ HIAP2), BIRC3 (cellular IAP2/cIAP2/HIAP1), BIRC4 (X-linked IAP/XIAP/hILP), BIRC5 (Survivin), BIRC6 (BIR containing ubiquitin conjugating enzyme/BRUCE/Apollon), BIRC7

\footnotetext{
${ }^{1}$ Emmy Noether Group of the DFG, Institute of Biochemistry II, Goethe University Medical School, Frankfurt, Germany

*Corresponding author: K Rajalingam, Emmy Noether Group of the DFG, Institute for Biochemistry II, Goethe University, Theodor Stern Kai 7, Frankfurt, Hessen 60590, Germany. Tel: + 49696301 5450; E-mail: Krishna@ biochem2.de

Keywords: IAPs; XIAP; cIAP1 BIR; tumour; migration; metastases

Abbreviations: IAP, inhibitor of apoptosis; BIR, baculovirus IAP repeat; RING, really interesting new gene; UBA, ubiquitin-associated domain; UBC, ubiquitin conjugation domain; LRR, leucine-rich repeats; CARD, caspase recruitment domain; PCD, programmed cell death; NLR, NOD-like receptor; IBM, IAP-binding motif; IAC, IAP antagonist compound; MALT, mucosa-associated lymphoid tissue; ALL, acute myeloid leukemia; NSCLC, non-small cell lung carcinoma; RCC, renal cell carcinoma; TRAMP, transgenic adenocarcinoma of mouse prostate; GEF, guanine nucleotide exchange factor; GAP, GTPase-activating protein; RhoGDI, rho GDPdissociation inhibitor; ECM, extracellular matrix; FA, focal adhesion; CGN, cerebellar granule neurons; EMT, epithelial-mesenchymal transition; MET, mesenchmalepithelial transition
}

Received 04.7.13; accepted 09.7.13; Edited by G Raschellá 


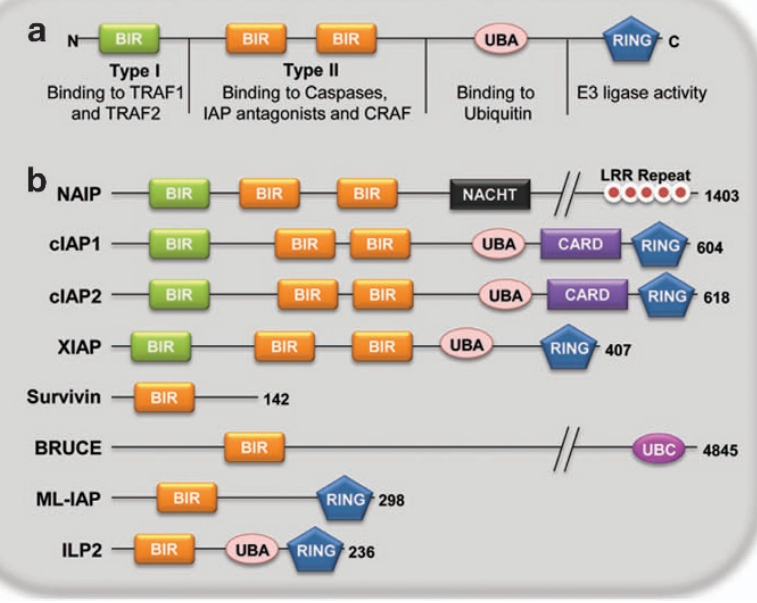

Figure 1 Domain architecture of mammalian IAPs. (a) A prototypical IAP is depicted consisting of Type I and Type II BIR domains, ubiquitin-binding domain and RING domain with their functions and molecular structures. (b) Various mammalian IAPs are depicted with their known functional domains. BIR, baculoviral IAP repeat domain; NACHT/NOD, nucleotide binding and oligomerization domain; LRR, leucine-rich repeats; UBA, ubiquitin-associated domain; CARD, caspase recruitment domain; RING, really interesting new gene domain; UBC, ubiquitin conjugating domain

(Melanoma IAP/ML-IAP/Livin) and BIRC8 (IAP-like protein 2/ hILP2/Ts-IAP). Apart from the BIR domains, there are various other structural motifs defining the characteristics of IAPs. NAIP has a NACHT domain and leucine-rich repeats (LRR) implicated in Nod-like receptor (NLR)-mediated innate immunity signaling. ${ }^{7}$ Another important domain is the really interesting new gene (RING) domain present in clAP1, clAP2, XIAP, ML-IAP and hILP2. This domain provides an E3 ubiquitin ligase activity to the proteins by virtue of which, it can promote attachment of monomeric ubiquitin or ubiquitin chains of various kinds to the substrate. RING domains of IAPs have been shown to be responsible for auto-ubiquitination, cross-ubiquitination of other IAPs and substrate ubiquitination. CIAP1, CIAP2, XIAP and hILP2 also have an ubiquitin-associated domain (UBA) ${ }^{8,9}$ UBA domain binds to monomeric ubiquitin as well as ubiquitin chains helping in protein complex assembly to promote various cell signaling events. ${ }^{10}$ BRUCE lacks both the RING as well as UBA domains but has an ubiquitin conjugation or UBC domain catalyzing the conjugation of ubiquitin to the substrate. clAP1 and clAP2 have a CARD domain (CAspase Recruitment Domain), which is also present in various components of apoptotic and inflammation signaling complexes like caspases (-1/-2/-4/-5/-9 and -13), Apaf-1, PIDD, RAIDD, NODs and RIP2. The role of CARD domain in IAPs has been unknown, though a recent study suggested its role in autoinhibition of the RING domain activity of $\mathrm{ClAP} 1^{11}$ (Figure 1).

As stated above, IAPs can be regulated by auto-ubiquitination and cross-ubiquitination via their RING domains. It has been reported that loss of one IAP leads to an increase in the protein levels of another IAP. ${ }^{12}$ Further, the RING domain of CIAP1 has been reported to mediate the degradation of other RING-bearing IAPs. ${ }^{13}$ In these lines, IAPs have been shown to exist as heteromeric complexes in the cytosol of many human cell lines. ${ }^{14}$ Further, a heteromeric complex of surivivin

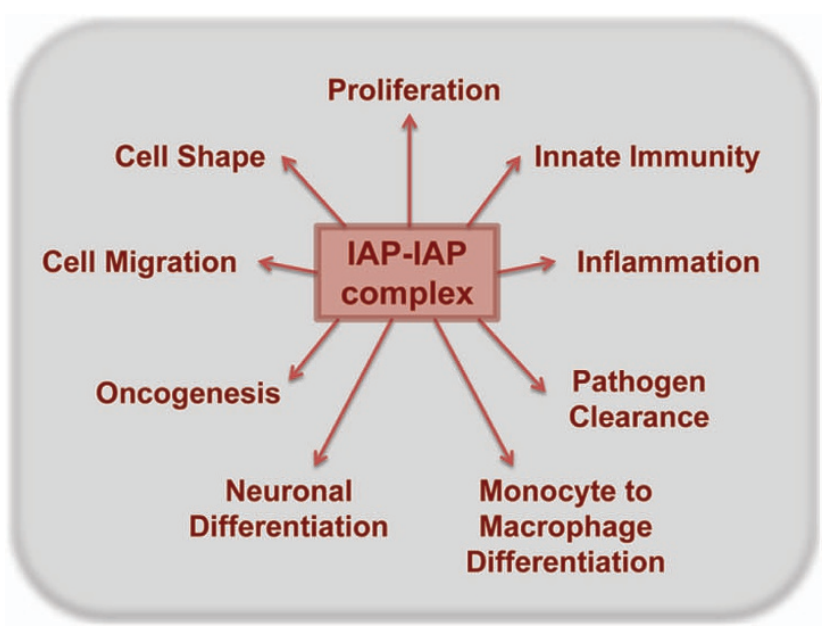

Figure 2 Cellular phenotypes mediated by IAP-IAP complexes. Depicted are the known cellular phenotypes that are regulated by IAPs. IAPs can form homomeric or hetermeric complexes within the cells and have a central role in various cellular signaling pathways that can be translated to various phenotypes

and XIAP has been shown to resist apoptosis. ${ }^{15}$ IAPs can also be regulated by certain endogenous inhibitors of IAPs like Smac/DIABLO, Omi/HtrA2, XAF1, ARTS and TWEAK. ${ }^{16-20}$ Smac/DIABLO, the most well-studied IAP inhibitor is a mitochondrial protein released into the cytosol during apoptotic induction. Upon release into the cytosol, Smac/DIABLO binds directly to XIAP by its N-terminal, IAP-binding motif (IBM). IBM interacts with BIR2 and BIR3 of XIAP, and thereby disrupts the function of XIAP to block caspase-3, -7 , and $-9 .{ }^{21}$ Smac has also been shown to trigger auto-ubiquitination of CIAPS, XIAP and ML-IAP leading to proteasomal degradation of CIAPs but not XIAP and ML-IAP. ${ }^{22}$

IAPs have come forth as vital signaling molecules at the crux of various cell death and survival pathways. Apart from apoptotic-caspase cascade, IAPs are essential modulators of innate immunity signaling, canonical and non-canonical NF- $\kappa$ B pathways as well as TGF $\beta$ signaling pathway ${ }^{23}$ (Figure 2). Their role as tumor modulators has been substantiated by differential expression of IAP family members in various malignancies. Elevated expression of IAPs in certain tumor types has been correlated with tumor survival and resistance to chemotherapy. So, a variety of antitumor therapeutics, especially small-molecule inhibitors against IAPs (IAP antagonist compounds (IAC), Smac mimetics) are being designed and clinically tested. ${ }^{24,25}$ Though several studies have demonstrated elevated levels of multiple IAPs in an array of human cancers as well as tumor models, a clinical correlation could not be established for many of them. Furthermore, the relative contribution of individual IAPs towards tumorigenesis and progression is far from clear. There have been opposing prognostic implications for IAPs in different tumor types, strongly suggesting that the role of IAPs in tumorigenesis is context- and cell type-dependent.

\section{Role of IAPs in Tumorigenesis and Tumor Progression}

IAPs correlated with negative prognosis. IAPs are overexpressed in a number of tumors and are recognized 
to regulate carcinogenesis at various stages. ClAP1 and clAP2 have been suggested as proto-oncogenes by various genetic studies. clAP1/2 and YAP (yes-associated protein) are a part of 11q21-11q23 amplifications observed in a variety of cancers like hepatocellular carcinoma, medulloblastoma, glioblastoma, gastric carcinoma, non-small cell lung carcinoma and osteosarcoma. ${ }^{26-29}$ Deletions of CARD and RING domains in clAP2 are linked to generation of an oncoprotein in MALT (mucosa-associated lymphoid tissue) lymphoma. ${ }^{30}$ clAP2, along with BAX and BMF has been proposed as a three-gene signature for acute myeloid leukemia (ALL) prognosis but there have been contrasting reports for the importance of elevated levels of IAPs in other forms of leukemias. ${ }^{31-34}$ Elevated levels of IAPs in bladder cancer and colorectal carcinoma correlated with progressive stages of tumor as well as decreased overall patient survival. ${ }^{35-38}$ In breast carcinoma, higher nuclear expression of XIAP correlated with lower patient survival. ${ }^{39}$ Similarly, in cervical squamous cell carcinoma, recurrence-free survival rates were lower with high levels of nuclear clAP1. ${ }^{40}$ Furthermore, enhanced expression of survivin, clAP1, clAP2 and XIAP has been observed in chemotherapy-induced multi-drug resistant multiple myeloma. ${ }^{41}$ Apart from IAPs, pro-apoptotic, endogenous IAP antagonists like Smac, Omi/ HtrA2, XAF1 and ARTS have also been characterized for cancer prognosis. ${ }^{42-45}$ Independent studies have shown that patients expressing higher levels of Smac have higher chances of recurrence-free survival in AML, breast cancer, NSCLC, RCC, bladder carcinoma and colorectal carcinoma, whereas lower levels have been associated with tumor metastasis and lower life expectancy. ${ }^{46-50}$ Studies with XAF1 confirmed its prognostic value in pancreatic cancer, squamous cell lung cancer and ovarian cancer. ${ }^{51,52}$ Low expression levels of XAF1 could be correlated with disease stage, differentiation status and lymph node metastasis in squamous cell lung cancer patients. ${ }^{53}$ Further, studies carried out by Elhasid et al. found a loss of ARTS protein expression in all malignant lymphoblasts in a majority of pediatric ALL patients, which was found to be reversed upon remission in almost all of them ${ }^{54}$ (Table 1 ).

IAPs correlated with positive prognosis. There have also been reports showing favorable cancer prognosis with elevated levels of IAPs. In case of NSCLC, a study by
Ferreira et al. ${ }^{55}$ reported that high XIAP levels correlated with lower proliferation rate and longer patient survival, suggesting it as a positive prognostic factor for NSCLC. Elevated ML-IAP expression has been determined as an independent favorable prognosis factor for pediatric ALL as well as relapse-free survival in $\mathrm{RCC}{ }^{56,57}$ In these lines, a recent study by Lazar et al. ${ }^{58}$ showed that high ML-IAP levels correlated with poor prognosis in patients that responded to an autologous melanoma vaccine. On the contrary, in patients that remained with active disease after treatment with melanoma vaccine, low to intermediate levels rather than absence of protein is associated with favorable prognosis due to paradoxical pro-apoptotic ML-IAP activity. ${ }^{20,58}$ Furthermore, higher levels of IAPs (BIRC1-5) were reported in prostate cancer cell lines as well as prostate cancer samples without any clinical correlation. ${ }^{59,60} \mathrm{How}-$ ever, some recent studies have identified XIAP expression as an independent favorable prognostic marker for longer relapse-free survival in prostate cancer patients (Table 2). IAPs have been recently recognized as crucial regulators of tumor cell migration and metastases. ${ }^{61} \mathrm{We}$ will be mainly focusing further on IAP-mediated cellular migration in physiological as well as patho-physiological context in this review.

\section{Cell Migration}

Migration is a complex and cell-type dependent fundamental process that underlies key biological phenomena like tissue formation and maintenance, regeneration as well as pathological conditions like cancer metastasis. While there are

Table 2 IAPs and positive prognosis

\begin{tabular}{|c|c|c|c|}
\hline Cancer type & $\begin{array}{l}\text { IAPs } \\
\text { involved }\end{array}$ & $\begin{array}{l}\text { Detection } \\
\text { parameter }\end{array}$ & References \\
\hline \multicolumn{4}{|c|}{ IAPs and positive prognosis } \\
\hline NSCLC & XIAP & Protein & Ferreira et al. $^{55}$ \\
\hline $\begin{array}{l}\text { Renal cell } \\
\text { carcinoma }\end{array}$ & ML-IAP & Protein & $\begin{array}{l}\text { Haferkamp } \\
\text { et al. }{ }^{57}\end{array}$ \\
\hline Pediatric ALL & ML-IAP & RNA and protein & Choi et al. ${ }^{56}$ \\
\hline Melanoma & ML-IAP & Protein & Lazar et al. ${ }^{58}$ \\
\hline Prostate cancer & XIAP & Protein & $\begin{array}{l}\text { Seligson } \\
\text { et al. }\end{array}$ \\
\hline
\end{tabular}

Various IAPs reported to be downregulated in cancers and/or linked to positive tumor prognosis are listed

Table 1 IAPs and negative prognosis

\begin{tabular}{|c|c|c|c|}
\hline Cancer type & IAPs involved & Detection parameter & References \\
\hline \multicolumn{4}{|l|}{ IAPs and negative prognosis } \\
\hline $\begin{array}{l}\text { Esophageal squamous cell carcinoma } \\
\text { SCLC and NSCLC }\end{array}$ & $\begin{array}{l}\text { ClAP1 and clAP2 } \\
\text { CIAP1 and clAP2 }\end{array}$ & $\begin{array}{l}\text { Genomic DNA and RNA (11q21-23 amplicon) } \\
\text { Genomic DNA and Protein (11q21-23 amplicon) }\end{array}$ & $\begin{array}{l}\text { Imoto et al. }{ }^{119} \\
\text { Dai et al. }\end{array}$ \\
\hline Hepatocellular carcinoma & ClAP1 & Genomic DNA and RNA (11q21-23 amplicon) & Zender et al. ${ }^{29}$ \\
\hline MALT Iymphoma & clAP2 & RNA ( $\mathrm{t}(11: 18)(\mathrm{q} 21: 21)$ translocation) & Dierlamm et al. ${ }^{120}$ \\
\hline Acute myeloid leukemia (ALL) & CIAP2 & RNA & Hess et al. ${ }^{33}$ \\
\hline Bladder cancer & XIAP & Protein and RNA & Li et al. ${ }^{36}$ \\
\hline & Nuclear clAP1 & Protein & Che et al. \\
\hline Colorectal cancer & $\begin{array}{l}\text { XIAP } \\
\text { CIAP2 }\end{array}$ & $\begin{array}{l}\text { RNA and protein } \\
\text { Protein }\end{array}$ & $\begin{array}{l}\text { Xiang et al. }{ }^{37} \\
\text { Krajewska et al. }\end{array}$ \\
\hline Breast cancer & Nuclear XIAP & Protein & Zhang et al. ${ }^{39}$ \\
\hline Cervical sqamous cell carcinoma & Nuclear clAP1 & Protein (resistance to radiotherapy) & Imoto et al. ${ }^{40}$ \\
\hline
\end{tabular}

Various IAPs reported to be upregulated in cancers and/or linked to negative tumor prognosis are listed 
various factors that influence cell shape and migration like cell-cell and cell-matrix adhesions, pericellular proteolysis, polarity, as well as the extracellular matrix (ECM), the basic cellular feature that drives this process is the actin cytoskeleton. Seminal work by Lauffenburger and Horwitz ${ }^{62}$ in 1996 proposed a five-step process for cell migration. The process of cell migration begins with protrusions formed by cell at the leading edge in response to an appropriate migration stimulus. This leads to the formation of focal adhesion (FA) complexes that help attach the cell to the ECM. In the event of secretion of proteases, matrix degradation occurs at the leading edge of the cell. This is followed by actomyosin contractility and finally the detachment of the rear end of the cell. ${ }^{62}$ While most of the studies on cell migration were performed in 2D matrices and substrates, recent studies with 3D matrices revealed that cells exploit a much greater range of protrusive structures to migrate through these matrices like filopodia and lobopodia. ${ }^{63}$ This accounts for some of the conflicting results obtained depending on the model system selected to study cell migration. Therefore, care should be taken to interpret the results from dissimilar model systems.

Owing to the integral role of the actin cytoskeleton in migration of cells, Rho GTPases, which are known to regulate many aspects of intracellular actin dynamics, have been highly implicated in this process. Rho GTPases are a family of 20 proteins, among which Rac1, RhoA and Cdc42 are the best studied. Seminal studies showed that each of these proteins have a role in actin cytoskeleton rearrangement; Rac1 was linked to the formation of lamellipodia, Cdc42 to filopodia and RhoA to stress fiber formation by generation of actomyosin contractility. ${ }^{64}$

Cells can migrate as single cells or as a group in clusters, sheets; this has led to the classification of cell migration into single-cell and collective cell migration. Single-cell migration can further be divided into mesenchymal and amoeboid forms of migration. Mesenchymal migration is characterized by an elongated morphology, high attachment of cells to the ECM via FA complexes, as well as secretion of proteases to degrade the ECM. Amoeboid movement is largely independent of cell-matrix contact and proteolytic degradation and the cells show a rounded morphology. Rac1 and Cdc42 have an important role at the leading edge of the cell in mesenchymal form of migration. Rac1 helps to initiate lamellipodium formation and Cdc42 maintains the directionality of the cell. ${ }^{65,66}$ RhoA is usually detected at the trailing edge of these cells where it facilitates in tail retraction. RhoA has a more prominent role in amoeboid movement via actomyosin contractility through myosin activation. ${ }^{67,68}$ Cdc42 is also implicated in amoeboid migration and invasion in melanoma cells. ${ }^{69}$

While cells preferentially employ one of the abovedescribed migration types, they have the ability to adapt to the changes in their microenvironment and switch from one mode of migration to the other. Thus, plasticity of cell migration has ample physiological and patho-physiological relevance. Rho GTPases have an integral role in this switch, with their activity often corresponding to the preferred mode of migration of a particular cell type. For example, RhoA activation is associated with amoeboid form of migration and Rac1 with mesenchymal mode of migration, although RhoA- mediated actomyosin contractility is also an essential component of mesenchymal migration contributing to tail retraction. Recent studies have also implicated other Rho GTPases in these processes; RhoE, for example, is downregulated in hepatocellular carcinoma and this is associated with poor prognosis due to loss of E-Cadherin at junctions, thus leading to tumor progression and metastasis. ${ }^{70,71}$

\section{Role of IAP-Mediated Signaling in Cell Migration}

IAPs in physiological forms of migration. The first evidence for the role of IAPs in cell migration was demonstrated by Geisbrecht and Montell in 2004 during their studies with border cell migration in Drosophila ovaries, an important phenomenon for oogenesis during embryonic development. The process of border cell migration exemplifies how cells of epithelial origin acquire migratory properties. They reported that expression of dominant-negative Rac1 (Rac1-N17) in border cells inhibits border cell migration, and hence, renders the fly infertile. Further, in a forward genetics screen, they found that when overexpressed, DIAP1 or Drosophila IAP1 can suppress Rac-N17-mediated border cell migration defect. This effect was mediated by the BIR domains of DIAP1 and was independent of its antiapoptotic activity as well as its RING domain. ${ }^{72}$ Furthermore, DIAP1 was found to interact with profilin, an actin-binding protein and binding partner for Rac1. This suggests a promigratory role of DIAP1 in actin polymerization via profilin to mediate border cell migration in Drosophila ovaries. In these lines, we have uncovered that XIAP and cIAP1 can function as the direct E3 ubiquitin ligase of Rac1 $1{ }^{73}$ Loss of these two IAPs stabilizes Rac1 and promotes an elongated-mesenchymal mode of migration in many primary and tumor cell lines (discussed below). This observation is in contradiction with the results found with DIAP1, but whether mammalian IAPs can bind to profilin and the physiological relevance of this interaction still need to be tested.

In collaboration with Reinhard Köster's group, we have shown a role for DrXIAP in migration of cerebellar granule neurons (CGNs) during cerebellar development in Danio rerio. We employed transgenic zebrafish strain to generate conditional expression of transgenes in the cells of the upper rhombic lip. Enhanced expression of DrXIAP in CGNs lead to a loss of cell polarity and cells were often found in the fourth ventricle forming clusters. These effects were Rac1-dependent as increasing the expression of wild-type Rac1 with DrXIAP could rescue the phenotype. ${ }^{73}$ Thus, DrXIAP shows an anti-migratory effect on progenitor cell migration during zebrafish brain development by regulating Rac1. We also observed that XIAP knockdown in immortalized cerebellar granular cells derived from mice showed enhanced Rac1 levels, suggesting an evolutionarily conserved role for IAPs in controlling Rac1 homeostasis.

IAPs have also been shown to modulate endothelial cell migration. Kim et al. ${ }^{74,75}$ found a role of XIAP in regulating endothelial cell survival and migration. They found that caveolin1 can bind to XIAP via its BIR3 domain, and thus, recruits XIAP to $\alpha 5$-integrin complex. XIAP also recruits FAK to this complex and was found to be essential for shear-stress- 
induced, Src-mediated Y567 phosphorylation of FAK and ERK $1 / 2$ activation. ${ }^{76}$ They also showed that XIAP could directly bind to FAK via FRNK domain of FAK and promote endothelial cell migration by inhibiting FRNK-mediated cell adhesion. ${ }^{77}$ As Rac1, FAK and integrins are vital to the dynamics of all forms of cell adhesion and migration, it is tempting to investigate the role of IAPs in other physiological forms of cell migration including wound healing and in immune cell responses. IAPs were shown to exhibit both pro- and anti-migratory functions in tumor cells, which have been discussed below.

Pro-migratory effects of IAPs in tumor cells. A recent study by Lopez et al. ${ }^{11}$ suggested that CARD domain of clAP1 prevents its auto-ubiquitination through intramolecular inhibition of RING dimerization and hence its E3 ubiquitin ligase activity. They further showed that CARD-mediated RING regulation had implications on cell proliferation and migration. clAP1 cooperates with Myc to drive cell proliferation by ubiquitination and degradation of myc antagonist, Mad1. By means of reconstitution studies in clAP1/2 DKO MEFs they could observe more RING activity in CARD deletion mutant of clAP1 as compared with WT cIAP1. Using the same strategy with scratch assays, they observed enhanced migration in mutant cIAP1 reconstituted cells as compared with WT clAP1 cells. This suggests a role for CARD domain in regulating clAP1-mediated cell migration. Furthermore, they demonstrated a loss of wound-healing ability in MCF-7 cells upon clAP1 knockdown, suggesting a pro-migratory role of clAP1 in these cells. Though this study finds a role for CARD domains in regulation of RING activity and migration, there have been other studies using IACmediated degradation of clAP1 that suggest a different mechanism of regulation of clAP1 stability. Report from Blankenship et al. ${ }^{8}$ using clAP1 WT and its CARD deletion mutant suggest that the linker region between BIR3 and CARD domain of CIAP1 and not the CARD domain per se is important for modulating its stability. Studies by Fairbrother et al. $^{24}$ suggest the role of BIR3-RING interactions in the modulation of RING E3 ligase activity of clAP1. ${ }^{78}$

Another study by Liu et al. ${ }^{79}$ attempts to define the role of XIAP-RING domain in cancer cell migration. It was shown that depletion of XIAP in HCT116 colorectal carcinoma cells leads to diminished migration in scratch assays and XIAPmediated cancer cell migration is RING domain-dependent. The same group also determined a role for XIAP-RhoGDI interaction via RING domain of XIAP to mediate cell motility by regulating actin cytoskeleton. XIAP was found to negatively regulate RhoGDI sumoylation at Lys-138 to promote cancer cell motility. ${ }^{80,81}$

Anti-migratory effects of IAPs in tumor cells. There have also been studies defining the anti-migratory effects of IAPs in tumor scenarios. We have shown that cIAP1, CIAP2, XIAP and ML-IAP can promote proteasomal degradation of C-RAF, a central kinase of the classical MAPK pathway that plays an important role in tumorigenesis downstream of Ras. $^{82,83}$ Knockdown of IAPs using siRNAs leads to enhanced lamellipodia and filopodia formation in HeLa cells as well as C-RAF-dependent enhanced cell migration. Oncogenic Ras mutations occur in $\sim 30 \%$ of all human cancers and C-RAF is pivotal to Ras signaling. C-RAF/MAPK pathway activation can promote cell survival by regulating expression/activity of BCL-2 family members. ${ }^{84} \mathrm{C}-\mathrm{RAF}$ can also directly restrain apoptosis by binding and inhibiting stress-induced kinase ASK-1. ${ }^{85}$ Furthermore, C-RAF can promote EMT, tissue invasion and metastasis by production of TGF $\beta$ and inhibition of Rho effector, ROCK2. ${ }^{86-88}$

Further work in these lines have demonstrated that knockdown of IAPs using an IAC lead to an elongated morphology in various primary and tumor cells as well as Rac1- and MAPKdependent enhanced migration in tumor cells. IAC-mediated knockdown of IAPs can lead to Rac1 stabilization and activation, leading to Rac1-dependent, enhanced mesenchymal-type of tumor migration ${ }^{73,89}$ (Figure 3 ). This migration phenotype could be recapitulated by employing early passage clAP1 $^{-1-}$ as well as $\mathrm{XIAP}^{-1-}$ MEFs. Knockout MEFs showed elongated morphology and migrated more efficiently as compared with strain-matched WT MEFs in a Rac1dependent manner (Figure 3). Most of the discrepancy observed with respect to pro- and anti-migratory effects of IAPs could be attributed to the difference in the cell types employed, as many of the migration-regulating molecules controlled by IAPs could promote or inhibit migration in a context-dependent manner.

Role of IAP-effector signaling in cell migration. The phenotype observed in our studies upon IAP knockdown using siRNAs and IACs resembles epithelial-mesenchymal transition (EMT) in the cells. ${ }^{73}$ EMT is an important cellular program occurring both during embryonic development as well as pathogenesis. Primary epithelial tumors can give rise to dissemination of single carcinoma cells by undergoing EMT, and thus, lead to tumor migration and metastasis. ${ }^{90}$ Pertinent to this, it was previously demonstrated that coordinated activation of Rac1 and the RAF/MAPK pathway is required for cell scattering and migration, key components of EMT upon activation of Ras in NBT II rat bladder

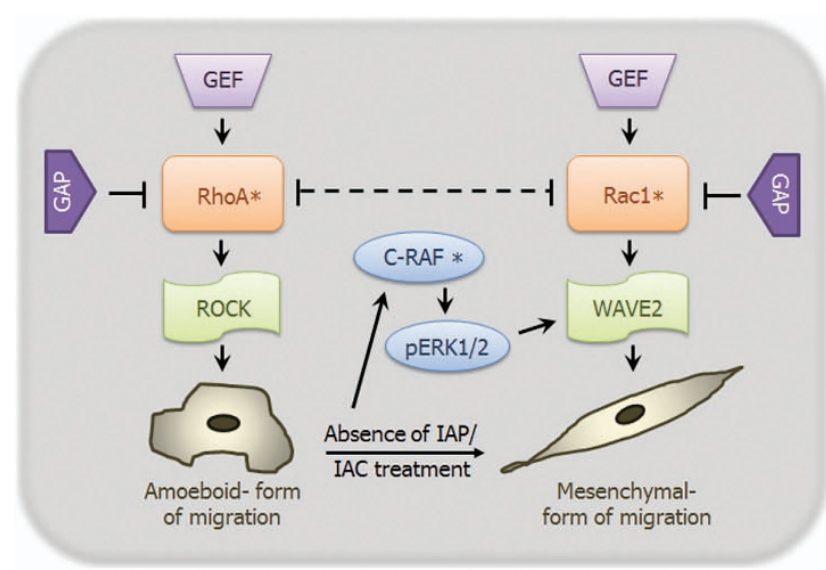

Figure 3 IAPs modulate cellular morphology and migration. Transient depletion of IAPs using siRNAs and IACs as well as CIAP1 and XIAP knockout MEFs show an elongated mesenchymal-like morphology and mesenchymal mode of migration (*indicates activation) 
carcinoma cell line. ${ }^{91}$ This is in line with our observations that coordinated activation of both C-RAF and Rac1 pathways leads to cell migration upon IAP depletion.

Apart from these reports, there have been various instances demonstrating that these pathways potentiate the effect of each other. A recent report describes that ERK2, a downstream kinase of Ras-Raf-MEK-ERK pathway, can directly phosphorylate components of WAVE2 complex, WAVE2 and Abi1, essential for interaction of WAVE complex with Arp2/3 and actin to mediate actin polymerization and lamellipodia formation. ${ }^{92}$ Rac1 is the direct activator of WAVE complex and it is now shown that MAPK activation can potentiate its effect. Conversely, Rac1 has been shown to potentiate Ras-dependent skin tumor formation by hyperactivation of MEK-ERK1/2 signaling by Rac1 effector, Pak1. ${ }^{93}$ Furthermore, RacGEF Tiam1 has been implicated tumor invasiveness and metastasis. ${ }^{94-97}$ Rac1 activation can promote both EMT and mesenchymal-epithelial transition (MET) by regulating assembly and disassembly of adherens junctions, and thereby has the ability to either prevent or facilitate tumor metastasis and secondary tumor formation. ${ }^{98-}$ 100 Rac1 activity is also vital for microtubule-induced FA disassembly for driving cell migration. ${ }^{101}$ Further, as previously stated, tumor cell plasticity is a major contributor towards metastasis. Rac1 activation drives mesenchymal mode of migration, which limits lung colonization in mice. ${ }^{102}$ Further, knockdown of IAPs can also lead to inactivation of RhoA ${ }^{73}$ In addition, unpublished observations from our lab reveal a direct interaction between IAPs and RhoA independent of activation status of RhoA. Therefore, it necessitates a careful examination of coordinated Rac1-RhoA signaling pathways to predict the final migration phenotype in IAPdepleted cells (Figure 4).

Apart from C-RAF, Rac1 and RhoA, IAPs can also mediate both canonical and non-canonical NF- $\kappa$ B pathways by ubiquitinating RIP and NIK kinases, respectively, at the interface of cell death/survival, inflammation and innate immune response as recently reviewed. ${ }^{23,24} \mathrm{NF}-\kappa \mathrm{B}$ pathway can be activated due to $\mathrm{TNF} \alpha$ secreted by activated macrophages, fibroblasts, Kupffer cells and a variety of tumor cells including breast carcinoma, colon carcinoma and B-cell lymphoma. Induction of NF- $\kappa \mathrm{B}$ and Akt signaling pathways by TNF $\alpha$ secretion inhibits GSK-3 $\beta$-mediated phosphorylation of Snail and $\beta$-catenin, inducing their stabilization and nuclear localization. ${ }^{103,104}$ Snail can interact with $\beta$-catenin and establish a positive feedback loop for Wnt-dependent transcription. ${ }^{105}$ Taken together, all the above signaling events contribute to angiogenic activity, accelerated EMT and tumor cell invasion and metastasis. NF- $\kappa$ B activation can also directly promote tumor survival and metastases. ${ }^{106-109} \mathrm{~A}$ recent study demonstrated a role for IAP-mediated regulation of non-canonical NF- $\kappa$ B signaling in modulating migration and invasion in glioblastoma cells in a preclinical tumor model. ${ }^{110}$ As IAPs can directly regulate the $\mathrm{NF}-\kappa \mathrm{B}$ pathway, they can either promote or inhibit tumor invasion and metastasis in a context-dependent manner. There has also been a report by Baumann et al. ${ }^{111}$ stating that C-RAF can synergize with another kinase, MEKK1 to activate NF- $\kappa$ B pathway, which adds to the intricacy of these signaling complexes (Figure 4).

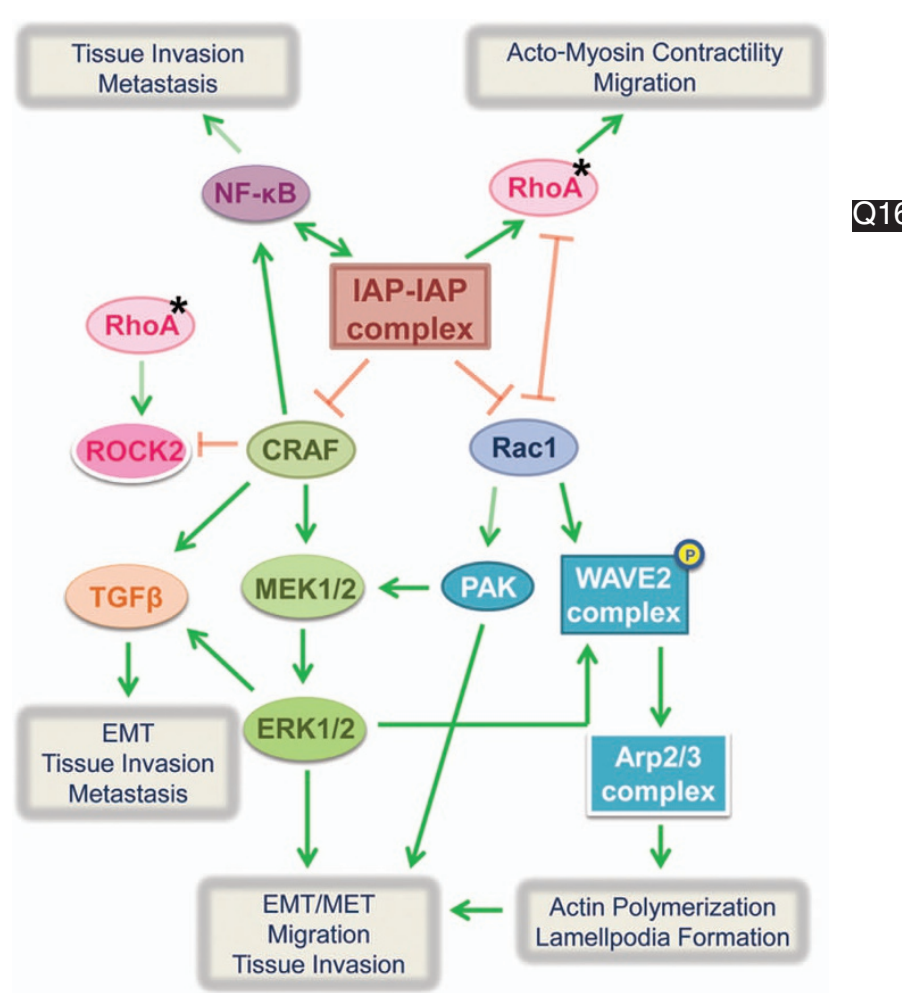

Figure 4 IAP-mediated signaling pathways involved in EMT/MET, cell migration, invasion and metastases. Shown is the representation of various cellular signaling pathways that are modulated by IAPs. IAPs regulate signal transduction via MAPK, RhoGTPase, NF- $\kappa$ B and several other pathways to modulate the cellular migration at endogenous levels as well as under tumor progression conditions. The cross talk between these various pathways might influence the migratory ability of the cells in a context-/cell-type-dependent manner ("denotes activation)

\section{Conclusion and Future Perspectives}

Cell migration studies suggest a context-dependent role of IAPs in tumor cell migration. The final test for lethality associated with tumor is its metastatic potential or ability to migrate from the site of primary tumor. Nearly $90 \%$ of tumor lethality can be attributed to metastases. Therefore, it is vital to determine the direct role of IAPs in tumor metastases. Hwang et al. ${ }^{112}$ examined the role of XIAP in prostate cancer development using TRAMP (transgenic adenocarcinoma of mouse prostate) model. They checked for the tumor growth and metastatic potential in wild-type and XIAP-deficient, immunocompetent TRAMP mice and found that XIAP deficiency led to an aggressive form of disease without any compensatory increase in the levels of clAP1 or clAP2 levels. ${ }^{112}$ Therefore, it can be surmised that though there are elevated levels of XIAP in prostate cancers, it may not be responsible for carcinogenesis and metastasis. Along similar lines, another study was carried out by Mehrotra et al. ${ }^{113}$ to investigate the combined influence of XIAP and Survivin using a mouse metastasis model as well as in vitro matrigel invasion assay. They injected tumor cells from two adenocarcinoma cell lines, HCT116 (colorectal) and MCF-7 (breast) directly into the spleen to check for liver metastasis in immunocompromised SCID mice. Using cell lines, either stably overexpressing Survivin or having a stable knockdown of XIAP or both, they could show a higher metastatic potential of injected 
tumor cells being correlated to higher expression levels of IAPs. ${ }^{113}$ Both the aforementioned studies are carried out in mouse models with dissimilar background (immunocompetent versus immunocompromised) using adenocarcinomas of different origin as a basis for their study and showed contrasting results on XIAP-mediated tumor metastasis. This calls for further elucidation of pathways regulated by IAPs under diverse patho-physiological conditions.

Further, tumor microenvironment is a complex concoction of interacting factors and trying to mimic a human tumor in vitro or using in vivo mouse models including genetically engineered and humanized models might not be a true representation of the scenario. Though mouse models have contributed greatly to our current knowledge base and treatment strategies, recapitulating the stochastic nature of human tumorigenesis in a model organism is not completely possible. ${ }^{114}$ There are numerous examples of preclinically successful drugs failing to deliver clinically leading to loss of enormous amount of time, efforts and money. Therefore, it is vital that we exercise caution while extrapolating results from various tumor models.

IAPs are a part of complex signaling network, regulating components responsible for a diverse array of migration phenotypes. Deciphering the individual contribution of these components for a particular context (cell type/tumor type/ stage) could determine the final fate of the cell. Therefore, it is also imperative that we recognize the underlying nature of the pathology for appropriate use of IAP-mediated cancer therapeutics. To improve the treatment efficacy of IAP antagonists, various combinatorial strategies for them including chemotherapy and radiotherapy have been tested pre-clinically. ${ }^{24}$ For instance, beneficial synergistic effects were observed when IAP antagonists are used in combination with death receptor agonists like TRAIL. ${ }^{115}$ Apart from this, recent study depicted combinatorial effect of Pak1, a downstream Rac effector, inhibition on IAP antagonist treatment in NSCLC cell lines, rendering these cells hypersensitive to apoptotic cell death. ${ }^{116}$ Development of combination therapy is being supported as it promotes better patient survival as shown recently in a metastatic breast cancer Phase III clinical trial. ${ }^{117}$ Combination therapy might promote synergistic effects leading to low drug dosage, as well as suppresses resistance to therapy if multiple cell survival pathways are targeted at once though there are chances of higher toxicity. ${ }^{118}$ Fortunately, clinical trials with IAP antagonists did not show any dose-limiting toxicity till date. ${ }^{24}$

In summary, a move towards IAP antagonist-based therapy should be pursued with caution as we still need better understanding of the complex signaling interplay in context of particular tumor types by using improved and multiple model systems. Further, as there might be a chance of enhanced cell migration and motility upon IAP inhibition in surviving tumor cells, enhancing the apoptotic potential and hampering the migratory potential of IAP antagonists by using cell death inducers and Pak1 antagonists, respectively, in combination promises to be a viable anticancer therapy.

\section{Conflict of Interest}

The authors declare no conflict of interest.
Acknowledgements. We would like to apologize to colleagues whose work is not cited because of space constraints. KR is supported through a PLUS3 fellowship from the Boehringer Ingelheim Foundation. We also acknowledge the support from CRC-128 (DFG)

1. Birnbaum MJ, Clem RJ, Miller LK. An apoptosis-inhibiting gene from a nuclear polyhedrosis virus encoding a polypeptide with Cys/His sequence motifs. J Virol 1994; 68 : 2521-2528.

2. Crook NE, Clem RJ, Miller LK. An apoptosis-inhibiting baculovirus gene with a zinc fingerlike motif. J Virol 1993; 67: 2168-2174.

3. Tsiatsiani L, Van Breusegem F, Gallois P, Zavialov A, Lam E, Bozhkov PV. Metacaspases. Cell Death Differ 2011; 18: 1279-1288.

4. Asplund-Samuelsson J, Bergman B, Larsson J. Prokaryotic caspase homologs: phylogenetic patterns and functional characteristics reveal considerable diversity. PLOS One 2012; 7: e49888.

5. Kazemzadeh L, Cvijovic M, Petranovic D. Boolean model of yeast apoptosis as a tool to study yeast and human apoptotic regulations. Front Physiol 2012; 3: 446

6. Walter D, Wissing S, Madeo F, Fahrenkrog B. The inhibitor-of-apoptosis protein Bir1p protects against apoptosis in $\mathrm{S}$. cerevisiae and is a substrate for the yeast homologue of Omi/HtrA2. J Cell Sci 2006; 119(Pt 9): 1843-1851.

7. Damiano JS, Oliveira V, Welsh K, Reed JC. Heterotypic interactions among NACHT domains: implications for regulation of innate immune responses. Biochem $\mathrm{J} 2004$; 381(Pt 1): 213-219.

8. Blankenship JW, Varfolomeev E, Goncharov T, Fedorova AV, Kirkpatrick DS, Izrael-Tomasevic A et al. Ubiquitin binding modulates IAP antagonist-stimulated proteasomal degradation of C-IAP1 and C-IAP2(1). Biochem J 2009; 417: 149-160.

9. Gyrd-Hansen M, Darding M, Miasari M, Santoro MM, Zender L, Xue W et al. IAPs contain an evolutionarily conserved ubiquitin-binding domain that regulates NF-kappaB as well as cell survival and oncogenesis. Nat Cell Biol 2008; 10: 1309-1317.

10. Husnjak K, Dikic I. Ubiquitin-binding proteins: decoders of ubiquitin-mediated cellular functions. Annu Rev Biochem 2012; 81: 291-322.

11. Lopez J, John SW, Tenev T, Rautureau GJ, Hinds MG, Francalanci F et al. CARD-mediated autoinhibition of cIAP1's E3 ligase activity suppresses cell proliferation and migration. Mol Cell 2011; 42: 569-583.

12. Conze DB, Albert L, Ferrick DA, Goeddel DV, Yeh WC, Mak T et al. Posttranscriptional downregulation of C-IAP2 by the ubiquitin protein ligase c-IAP1 in vivo. Mol Cell Biol 2005; 25: 3348-3356.

13. Cheung HH, Plenchette S, Kern CJ, Mahoney DJ, Korneluk RG. The RING domain of ClAP1 mediates the degradation of RING-bearing inhibitor of apoptosis proteins by distinct pathways. Mol Biol Cell 2008; 19: 2729-2740.

14. Rajalingam $K$, Sharma $M$, Paland $N$, Hurwitz $R$, Thieck $O$, Oswald $M$ et al. IAP-IAP complexes required for apoptosis resistance of $\mathrm{C}$. trachomatis-infected cells. PLOS Pathog 2006; 2: e114.

15. Dohi T, Okada K, Xia F, Wilford CE, Samuel T, Welsh K et al. An IAP-IAP complex inhibits apoptosis. J Biol Chem 2004; 279: 34087-34090.

16. Wu G, Chai J, Suber TL, Wu JW, Du C, Wang X et al. Structural basis of IAP recognition by Smac/DIABLO. Nature 2000; 408: 1008-1012.

17. Suzuki $Y$, Imai $Y$, Nakayama H, Takahashi K, Takio K, Takahashi R. A serine protease, $\mathrm{HtrA2}$, is released from the mitochondria and interacts with XIAP, inducing cell death. Mol Cell 2001; 8: 613-621.

18. Hegde R, Srinivasula SM, Zhang Z, Wassell R, Mukattash R, Cilenti L et al. Identification of $\mathrm{Omi} / \mathrm{HtrA2}$ as a mitochondrial apoptotic serine protease that disrupts inhibitor of apoptosis protein-caspase interaction. J Biol Chem 2002; 277: 432-438.

19. Gottfried $Y$, Rotem A, Lotan R, Steller H, Larisch S. The mitochondrial ARTS protein promotes apoptosis through targeting XIAP. EMBO J 2004; 23: 1627-1635.

20. Nachmias B, Ashhab Y, Ben-Yehuda D. The inhibitor of apoptosis protein family (IAPs): an emerging therapeutic target in cancer. Semin Cancer Biol 2004; 14: 231-243.

21. Salvesen GS, Duckett CS. IAP proteins: blocking the road to death's door. Nat Rev Mol Cell Biol 2002; 3: 401-410.

22. Yang QH, Du C. Smac/DIABLO selectively reduces the levels of c-IAP1 and c-IAP2 but not that of XIAP and livin in HeLa cells. J Biol Chem 2004; 279: 16963-16970.

23. Gyrd-Hansen M, Meier P. IAPs: from caspase inhibitors to modulators of NF-kappaB, inflammation and cancer. Nat Rev Cancer 2010; 10: 561-574.

24. Fulda S, Vucic D, Targeting IAP. proteins for therapeutic intervention in cancer. Nat Rev Drug Discov 2012; 11: 109-124.

25. Wright CW, Duckett CS. Reawakening the cellular death program in neoplasia through the therapeutic blockade of IAP function. J Clin Invest 2005; 115: 2673-2678.

26. Ma O, Cai WW, Zender L, Dayaram T, Shen J, Herron AJ et al. MMP13, Birc2 (clAP1), and Birc3 (cIAP2), amplified on chromosome 9, collaborate with p53 deficiency in mouse osteosarcoma progression. Cancer Res 2009; 69: 2559-2567.

27. Dai Z, Zhu WG, Morrison CD, Brena RM, Smiraglia DJ, Raval A et al. A comprehensive search for DNA amplification in lung cancer identifies inhibitors of apoptosis cIAP1 and cIAP2 as candidate oncogenes. Hum Mol Genet 2003; 12: 791-801.

28. LaCasse EC, Mahoney DJ, Cheung HH, Plenchette S, Baird S, Korneluk RG. IAP-targeted therapies for cancer. Oncogene 2008; 27: 6252-6275. 
29. Zender L, Spector MS, Xue W, Flemming P, Cordon-Cardo C, Silke J et al. Identification and validation of oncogenes in liver cancer using an integrative oncogenomic approach. Cell 2006; 125: 1253-1267.

30. Rosebeck S, Madden L, Jin X, Gu S, Apel IJ, Appert A et al. Cleavage of NIK by the API2MALT1 fusion oncoprotein leads to noncanonical NF-kappaB activation. Science 2011 331: 468-472.

31. Carter BZ, Kornblau SM, Tsao T, Wang RY, Schober WD, Milella M et al. Caspaseindependent cell death in AML: caspase inhibition in vitro with pan-caspase inhibitors or in vivo by XIAP or Survivin does not affect cell survival or prognosis. Blood 2003; 102 $4179-4186$.

32. Grzybowska-Izydorczyk O, Cebula B, Robak T, Smolewski P. Expression and prognostic significance of the inhibitor of apoptosis protein (IAP) family and its antagonists in chronic lymphocytic leukaemia. Eur J Cancer 2010; 46: 800-810.

33. Hess CJ, Berkhof J, Denkers F, Ossenkoppele GJ, Schouten JP, Oudejans JJ et al. Activated intrinsic apoptosis pathway is a key related prognostic parameter in acute myeloid leukemia. J Clin Oncol 2007; 25: 1209-1215.

34. Tamm I, Richter S, Scholz F, Schmelz K, Oltersdorf D, Karawajew L et al. XIAP expression correlates with monocytic differentiation in adult de novo AML: impact on prognosis. Hematol J 2004; 5: 489-495.

35. Krajewska M, Kim H, Kim C, Kang H, Welsh K, Matsuzawa S et al. Analysis of apoptosis protein expression in early-stage colorectal cancer suggests opportunities for new prognostic biomarkers. Clin Cancer Res 2005; 11: 5451-5461.

36. Li M, Song T, Yin ZF, Na YQ. XIAP as a prognostic marker of early recurrence of nonmuscular invasive bladder cancer. Chin Med J (Engl) 2007; 120: 469-473.

37. Xiang G, Wen X, Wang H, Chen K, Liu H. Expression of X-linked inhibitor of apoptosis protein in human colorectal cancer and its correlation with prognosis. J Surg Oncol 2009; 100: 708-712.

38. Che X, Yang D, Zong $\mathrm{H}$, Wang J, Li X, Chen $\mathrm{F}$ et al. Nuclear clAP1 overexpression is a tumor stage- and grade-independent predictor of poor prognosis in human bladder cancer patients. Urol Oncol 2012; 30: 450-456.

39. Zhang Y, Zhu J, Tang Y, Li F, Zhou H, Peng B et al. X-linked inhibitor of apoptosis positive nuclear labeling: a new independent prognostic biomarker of breast invasive ductal carcinoma. Diagn Pathol 2011; 6: 49

40. Imoto I, Tsuda H, Hirasawa A, Miura M, Sakamoto M, Hirohashi S et al. Expression of CIAP1, a target for $11 \mathrm{q} 22$ amplification, correlates with resistance of cervical cancers to radiotherapy. Cancer Res 2002; 62: 4860-4866.

41. Nakagawa Y, Abe S, Kurata M, Hasegawa M, Yamamoto K, Inoue M et al. IAP family protein expression correlates with poor outcome of multiple myeloma patients in association with chemotherapy-induced overexpression of multidrug resistance genes. Am J Hematol 2006; 81: 824-831.

42. Plenchette $S$, Cheung HH, Fong WG, LaCasse EC, Korneluk RG. The role of XAF1 in cancer. Curr Opin Investig Drugs 2007; 8: 469-476.

43. Martinez-Ruiz G, Maldonado V, Ceballos-Cancino G, Grajeda JP, Melendez-Zajgla J. Role of Smac/DIABLO in cancer progression. J Exp Clin Cancer Res 2008; 27: 48 .

44. Elhasid R, Larisch S. ARTS-based anticancer therapy: taking aim at cancer stem cells. Future Oncol 2011; 7: 1185-1194.

45. Skorko-Glonek J, Zurawa-Janicka D, Koper T, Jarzab M, Figaj D, Glaza P et al. HtrA protease family as therapeutic targets. Curr Pharm Des 2013; 19: 977-1009.

46. Mizutani $\mathrm{Y}$, Nakanishi H, Yamamoto $\mathrm{K}$, Li YN, Matsubara H, Mikami $\mathrm{K}$ et al. Downregulation of Smac/DIABLO expression in renal cell carcinoma and its prognostic significance. J Clin Oncol 2005; 23: 448-454.

47. Mizutani $Y$, Katsuoka $Y$, Bonavida B. Prognostic significance of second mitochondriaderived activator of caspase (Smac/DIABLO) expression in bladder cancer and target for therapy. Int J Oncol 2010; 37: 503-508

48. Endo K, Kohnoe S, Watanabe A, Tashiro H, Sakata H, Morita M et al. Clinical significance of Smac/DIABLO expression in colorectal cancer. Oncol Rep 2009; 21: 351-355.

49. Pluta A, Wrzesien-Kus A, Cebula-Obrzut B, Wolska A, Szmigielska-Kaplon A, Czemerska $M$ et al. Influence of high expression of Smac/DIABLO protein on the clinical outcome in acute myeloid leukemia patients. Leuk Res 2010; 34: 1308-1313.

50. Pluta P, Cebula-Obrzut B, Ehemann V, Pluta A, Wierzbowska A, Piekarski J et al. Correlation of Smac/DIABLO protein expression with the clinico-pathological features of breast cancer patients. Neoplasma 2011; 58: 430-435.

51. Huang J, Yao WY, Zhu Q, Tu SP, Yuan F, Wang HF et al. XAF1 as a prognostic biomarker and therapeutic target in pancreatic cancer. Cancer Sci 2010; 101: 559-567.

52. Wang $Y$, Mao H, Hao Q, Yang Y, Shen L, Huang $S$ et al. Association of expression of XIAP-associated factor 1 (XAF1) with clinicopathologic factors, overall survival, microvessel density and cisplatin-resistance in ovarian cancer. Regul Pept 2012; 178: $36-42$.

53. Chen YB, Shu J, Yang WT, Shi L, Guo XF, Wang FG et al. XAF1 as a prognostic biomarker and therapeutic target in squamous cell lung cancer. Chin Med J (Engl) 2011; 124: 3238-3243.

54. Elhasid R, Sahar D, Merling A, Zivony Y, Rotem A, Ben-Arush M et al. Mitochondrial pro-apoptotic ARTS protein is lost in the majority of acute lymphoblastic leukemia patients. Oncogene 2004; 23: 5468-5475

55. Ferreira CG, van der Valk $P$, Span SW, Ludwig I, Smit EF, Kruyt FA et al. Expression of $X$-linked inhibitor of apoptosis as a novel prognostic marker in radically resected non-small cell lung cancer patients. Clin Cancer Res 2001; 7: 2468-2474.
56. Choi J, Hwang YK, Sung KW, Lee SH, Yoo KH, Jung HL et al. Expression of Livin, an antiapoptotic protein, is an independent favorable prognostic factor in childhood acute lymphoblastic leukemia. Blood 2007; 109: 471-477.

57. Haferkamp A, Bedke J, Vetter C, Pritsch M, Wagener N, Buse S et al. High nuclear Livin expression is a favourable prognostic indicator in renal cell carcinoma. BJU Int 2008; 102 1700-1706.

58. Lazar I, Perlman R, Lotem M, Peretz T, Ben-Yehuda D, Kadouri L. The clinical effect of the inhibitor of apopotosis protein livin in melanoma. Oncology 2012; 82: 197-204.

59. Krajewska M, Krajewski S, Banares S, Huang X, Turner B, Bubendorf L et al. Elevated expression of inhibitor of apoptosis proteins in prostate cancer. Clin Cancer Res 2003; 9: 4914-4925.

60. Seligson DB, Hongo F, Huerta-Yepez S, Mizutani Y, Miki T, Yu H et al. Expression of $\mathrm{X}$-linked inhibitor of apoptosis protein is a strong predictor of human prostate cancer recurrence. Clin Cancer Res 2007; 13: 6056-6063.

61. Kenneth NS, Duckett CS. IAP proteins: regulators of cell migration and development. Curr Opin Cell Biol 2012; 24: 871-875.

62. Lauffenburger DA, Horwitz AF. Cell migration: a physically integrated molecular process. Cell 1996; 84: 359-369.

63. Friedl P, Sahai E, Weiss S, Yamada KM. New dimensions in cell migration. Nat Rev Mol Cell Biol 2012; 13: 743-747.

64. Etienne-Manneville S, Hall A. Rho GTPases in cell biology. Nature 2002; 420: 629-635.

65. Ridley AJ, Schwartz MA, Burridge K, Firtel RA, Ginsberg MH, Borisy G et al. Cell migration: integrating signals from front to back. Science 2003; 302: 1704-1709.

66. Etienne-Manneville S, Hall A. Integrin-mediated activation of Cdc42 controls cell polarity in migrating astrocytes through PKCzeta. Cell 2001; 106: 489-498.

67. Friedl P. To adhere or not to adhere? Nat Rev Mol Cell Biol 2010; 11: 3

68. Sahai E, Marshall CJ. Differing modes of tumor cell invasion have distinct requirements for Rho/ROCK signaling and extracellular proteolysis. Nat Cell Biol 2003; 5: 711-719.

69. Gadea G, Sanz-Moreno V, Self A, Godi A, Marshall CJ. DOCK10-mediated Cdc42 activation is necessary for amoeboid invasion of melanoma cells. Curr Biol 2008; 18: $1456-1465$.

70. Luo H, Dong Z, Zou J, Zeng Q, Wu D, Liu L. Down-regulation of RhoE is associated with progression and poor prognosis in hepatocellular carcinoma. J Surg Oncol 2012; 105 699-704.

71. Grise F, Sena S, Bidaud-Meynard A, Baud J, Hiriart JB, Makki K et al. Rnd3/RhoE Is down-regulated in hepatocellular carcinoma and controls cellular invasion. Hepatology 2012; 55: 1766-1775.

72. Geisbrecht ER, Montell DJ. A role for Drosophila IAP1-mediated caspase inhibition in Rac-dependent cell migration. Cell 2004; 118: 111-125.

73. Oberoi TK, Dogan T, Hocking JC, Scholz RP, Mooz J, Anderson CL et al. IAPs regulate the plasticity of cell migration by directly targeting Rac1 for degradation. EMBO J 2012; 31: 14-28.

74. Kim J, Park J, Choi S, Chi SG, Mowbray AL, Jo H et al. X-linked inhibitor of apoptosis protein is an important regulator of vascular endothelial growth factor-dependent bovine aortic endothelial cell survival. Circ Res 2008; 102: 896-904.

75. Kim J, Ahn S, Ko YG, Boo YC, Chi SG, Ni CW et al. X-linked inhibitor of apoptosis protein controls alpha5-integrin-mediated cell adhesion and migration. Am J Physiol Heart Circ Physiol 2010; 299: H300-H309.

76. Ahn S, Park H. XIAP is essential for shear stress-enhanced Tyr-576 phosphorylation of FAK. Biochem Biophys Res Commun 2010; 399: 256-261.

77. Ahn S, Kim HJ, Chi SG, Park H. XIAP reverses various functional activities of FRNK in endothelial cells. Biochem Biophys Res Commun 2012; 419: 419-424.

78. Dueber EC, Schoeffler AJ, Lingel A, Elliott JM, Fedorova AV, Giannetti AM et al. Antagonists induce a conformational change in CIAP1 that promotes autoubiquitination. Science 2011; 334: 376-380.

79. Liu J, Zhang D, Luo W, Yu J, Li J, Yu Y et al. E3 ligase activity of XIAP RING domain is required for XIAP-mediated cancer cell migration, but not for its RhoGDI binding activity PLoS One 2012; 7: e35682.

80. Liu J, Zhang D, Luo W, Yu Y, Yu J, Li J et al. X-linked inhibitor of apoptosis protein (XIAP) mediates cancer cell motility via Rho GDP dissociation inhibitor (RhoGDI)-dependent regulation of the cytoskeleton. J Biol Chem 2011; 286: 15630-15640.

81. Yu J, Zhang D, Liu J, Li J, Yu Y, Wu XR et al. RhoGDI SUMOylation at Lys-138 increases its binding activity to Rho GTPase and its inhibiting cancer cell motility. J Biol Chem 2012 287: $13752-13760$.

82. Dogan T, Harms GS, Hekman M, Karreman C, Oberoi TK, Alnemri ES et al. X-linked and cellular IAPs modulate the stability of C-RAF kinase and cell motility. Nat Cell Biol 2008. 10: $1447-1455$.

83. Oberoi-Khanuja TK, Karreman C, Larisch S, Rapp UR, Rajalingam K. Role of melanoma inhibitor of apoptosis (ML-IAP) protein, a member of the baculoviral IAP repeat (BIR) domain family, in the regulation of C-RAF kinase and cell migration. J Biol Chem 2012; 287: 28445-28455.

84. Balmanno K, Cook SJ. Tumor cell survival signaling by the ERK1/2 pathway. Cell Death Differ 2009; 16: 368-377.

85. Chen J, Fujii K, Zhang L, Roberts T, Fu H. Raf-1 promotes cell survival by antagonizing apoptosis signal-regulating kinase 1 through a MEK-ERK independent mechanism. Proc Natl Acad Sci USA 2001; 98: 7783-7788. 
86. Lehmann K, Janda E, Pierreux CE, Rytomaa M, Schulze A, McMahon M et al. Raf induces TGFbeta production while blocking its apoptotic but not invasive responses: a mechanism leading to increased malignancy in epithelial cells. Genes Dev 2000; 14 2610-2622.

87. Janda E, Lehmann K, Killisch I, Jechlinger M, Herzig M, Downward J et al. Ras and TGF[beta] cooperatively regulate epithelial cell plasticity and metastasis: dissection of Ras signaling pathways. J Cell Biol 2002; 156: 299-313.

88. Ehrenreiter K, Piazzolla D, Velamoor V, Sobczak I, Small JV, Takeda J et al. Raf-1 regulates Rho signaling and cell migration. J Cell Biol 2005; 168: 955-964.

89. Oberoi-Khanuja TK, Rajalingam K. IAPs as E3 ligases of Rac1: shaping the move. Small GTPases 2012; 3: 131-136.

90. Thiery JP. Epithelial-mesenchymal transitions in tumor progression. Nat Rev Cancer 2002; 2: 442-454.

91. Edme N, Downward J, Thiery JP, Boyer B. Ras induces NBT-II epithelial cell scattering through the coordinate activities of Rac and MAPK pathways. J Cell Sci 2002; 115(Pt 12): 2591-2601.

92. Mendoza MC, Er EE, Zhang W, Ballif BA, Elliott HL, Danuser G et al. ERK-MAPK drives lamellipodia protrusion by activating the WAVE2 regulatory complex. Mol Cell 2011; 41: 661-671.

93. Wang Z, Pedersen E, Basse A, Lefever T, Peyrollier K, Kapoor S et al. Rac1 is crucial for Ras-dependent skin tumor formation by controlling Pak1-Mek-Erk hyperactivation and hyperproliferation in vivo. Oncogene 2010; 29: 3362-3373.

94. Malliri A, van der Kammen RA, Clark K, van der Valk M, Michiels F, Collard JG. Mice deficient in the Rac activator Tiam1 are resistant to Ras-induced skin tumors. Nature 2002; 417: 867-871.

95. Xu K, Rajagopal S, Klebba I, Dong S, Ji Y, Liu J et al. The role of fibroblast Tiam1 in tumor cell invasion and metastasis. Oncogene 2010; 29: 6533-6542.

96. Mertens AE, Rygiel TP, Olivo C, van der Kammen R, Collard JG. The Rac activator Tiam1 controls tight junction biogenesis in keratinocytes through binding to and activation of the Par polarity complex. J Cell Biol 2005; 170: 1029-1037.

97. Wang S, Watanabe T, Matsuzawa K, Katsumi A, Kakeno M, Matsui T et al. Tiam1 interaction with the PAR complex promotes talin-mediated Rac1 activation during polarized cell migration. J Cell Biol 2012; 199: 331-345.

98. Hordijk PL, ten Klooster JP, van der Kammen RA, Michiels F, Oomen LC, Collard JG. Inhibition of invasion of epithelial cells by Tiam1-Rac signaling. Science 1997; 278: 1464-1466.

99. Fischer RS, Zheng Y, Quinlan MP. Rac1 and extracellularly regulated kinase activation are sufficient for E1A-dependent cooperative transformation of primary epithelial cells, but progression can only be modulated by E1A or Rac1. Cell Growth Differ 1998; 9: 209-221.

100. Potempa S, Ridley AJ. Activation of both MAP kinase and phosphatidylinositide 3-kinase by Ras is required for hepatocyte growth factor/scatter factor-induced adherens junction disassembly. Mol Biol Cell 1998; 9: 2185-2200.

101. Rooney C, White G, Nazgiewicz A, Woodcock SA, Anderson KI, Ballestrem C et al. The Rac activator STEF (Tiam2) regulates cell migration by microtubule-mediated focal adhesion disassembly. EMBO Rep 2010; 11: 292-298.

102. Sanz-Moreno V, Gadea G, Ahn J, Paterson H, Marra P, Pinner S et al. Rac activation and inactivation control plasticity of tumor cell movement. Cell 2008; 135: 510-523.

103. Oguma K, Oshima H, Aoki M, Uchio R, Naka K, Nakamura S et al. Activated macrophages promote Wnt signaling through tumor necrosis factor-alpha in gastric tumo cells. EMBO J 2008; 27: 1671-1681

104. Wu Y, Deng J, Rychahou PG, Qiu S, Evers BM, Zhou BP. Stabilization of snail by NFkappaB is required for inflammation-induced cell migration and invasion. Cancer Cell 2009; 15: 416-428.
105. Stemmer V, de Craene B, Berx G, Behrens J. Snail promotes Wnt target gene expression and interacts with beta-catenin. Oncogene 2008; 27: 5075-5080.

106. Shishodia S, Aggarwal BB. Nuclear factor-kappaB activation mediates cellular transformation, proliferation, invasion angiogenesis and metastasis of cancer. Cancer Treat Res 2004; 119: 139-173.

107. Montesano R, Soulie P, Eble JA, Carrozzino F. Tumor necrosis factor alpha confers an invasive, transformed phenotype on mammary epithelial cells. J Cell Sci 2005; 118(Pt 15): 3487-3500.

108. Hagemann T, Wilson J, Kulbe H, Li NF, Leinster DA, Charles K et al. Macrophages induce invasiveness of epithelial cancer cells via NF-kappa B and JNK. J Immunol 2005; 175: 1197-1205.

109. Johnston DA, Dong B, Hughes CC. TNF induction of jagged-1 in endothelial cells is NFkappaB-dependent. Gene 2009; 435: 36-44

110. Tchoghandjian A, Jennewein C, Eckhardt I, Rajalingam K, Fulda S. Identification of non-canonical NF-kappaB signaling as a critical mediator of Smac mimeticstimulated migration and invasion of glioblastoma cells. Cell Death Dis 2013; 4: e564.

111. Baumann B, Weber CK, Troppmair J, Whiteside S, Israel A, Rapp UR et al. Raf induces NF-kappaB by membrane shuttle kinase MEKK1, a signaling pathway critical for transformation. Proc Natl Acad Sci USA 2000; 97: 4615-4620.

112. Hwang $C$, Oetien KA, Kosoff D, Woino KJ, Albertelli MA, Dunn RL et al. X-linked inhibito of apoptosis deficiency in the TRAMP mouse prostate cancer model. Cell Death Differ 2008; 15: 831-840.

113. Mehrotra S, Languino LR, Raskett CM, Mercurio AM, Dohi T, Altieri DC. IAP regulation of metastasis. Cancer Cell 2010; 17: 53-64.

114. Cook N, Jodrell DI, Tuveson DA. Predictive in vivo animal models and translation to clinical trials. Drug Discov Today 2012; 17: 253-260.

115. Dai Y, Liu M, Tang W, Li Y, Lian J, Lawrence TS et al. A Smac-mimetic sensitizes prostate cancer cells to TRAIL-induced apoptosis via modulating both IAPs and NF-kappaB. BMC Cancer 2009; 9: 392

116. Ong CC, Jubb AM, Haverty PM, Zhou W, Tran V, Truong T et al. Targeting p21-activated kinase 1 (PAK1) to induce apoptosis of tumor cells. Proc Natl Acad Sci USA 2011; 108: 7177-7182.

117. Mehta RS, Barlow WE, Albain KS, Vandenberg TA, Dakhil SR, Tirumali NR et al. Combination anastrozole and fulvestrant in metastatic breast cancer. N Engl J Med 2012; 367: 435-444.

118. Woodcock J, Griffin JP, Behrman RE. Development of novel combination therapies. $N$ Engl J Med 2011; 364: 985-987.

119. Imoto I, Yang ZQ, Pimkhaokham A, Tsuda H, Shimada Y, Imamura M et al. Identification of clAP1 as a candidate target gene within an amplicon at 11q22 in esophageal squamous cell carcinomas. Cancer Res 2001; 61: 6629-6634.

120. Dierlamm J, Baens M, Wlodarska I, Stefanova-Ouzounova M, Hernandez JM, Hossfeld DK et al. The apoptosis inhibitor gene API2 and a novel $18 \mathrm{q}$ gene, MLT, are recurrently rearranged in the $\mathrm{t}(11 ; 18)(\mathrm{q} 21 ; \mathrm{q} 21)$ associated with mucosa-associated lymphoid tissue lymphomas. Blood 1999; 93: 3601-3609.

(i) Cell Death and Disease is an open-access journal published by Nature Publishing Group. This work is licensed under a Creative Commons Attribution 3.0 Unported License. To view a copy of this license, visit http://creativecommons.org/ licenses/by/3.0/ 